\title{
Förändringar och nya riktningar inom human service
}

\section{ELISABETH BERG}

I detta temanummer av Socialvetenskaplig Tidskrift är avsikten att sätta fokus på förändringar och nya riktningar i människobehandlande organisationer ${ }^{1}$. Förändring är en aspekt av alla organisatoriska, sociala, politiska och ekonomiska aktiviteter. Det har dock varit särskilt snabba och långtgående förändringar av den offentliga servicen i människobehandlande organisationer, förändringar som har intensifierats av den fortskridande finanspolitiska krisen. Temanumret baseras på ett urval av konferenspapper från Dilemmas konferens 2010, där deltagare har skickat in sina artiklar och genomgått granskning av två oberoende referees. Temanumret avser att fokusera skilda områden inom den offentliga sektorn i Sverige och i ett internationellt sammanhang - främst Västeuropa och Tyskland - samt förändringar för ledningen från en organisatorisk synvinkel. Det är viktigt att understryka att målsättningen inte är att analysera de sociala förändringar som har skett i relation till den ekonomiska krisen eller att ge en kartläggning av välfärden och dess förändring, det är något som skulle

Elisabeth Berg är professor i sociologi vid Luleå tekniska universitet. vara en omöjlig uppgift. I denna introduktion ges en översiktlig bakgrund till förändringarna i områden som är relaterade till välfärdsstaten, offentliga sektorn och socialpolitiken, samt konsekvenser av en ökande nyliberalisering i samhället.

I Sverige började välfärdsstaten som term användas efter 1945 men begreppet dök upp redan i slutet av 1880-talet när Tyskland började använda Sozialstat för de nationer som tog ett ansvar för sina medborgares sociala situation (Olofsson 2009:7). Idén om välfärdstaten var en följd av politiska och ekonomiska motsättningar där idén om full sysselsättning och socialpolitiska reformer skulle ge en social och ekonomisk stabilitet till medborgare och tillfredsställa individens subjektiva och objektiva sociala behov (Olofsson 2009). Staten har dock inte monopol på välfärdsservice, utan privat tillhandahållande av hälso- och soci-

1 Offentliga myndigheter och organisationer (i vissa fall vinstdrivande) som har till uppgift att arbeta med utbildning, hälso- och sjukvård och sociala frågor, där människor på ett eller annat sätt får stöd, hjälp, service eller behandling (se Danermark \& Kullberg, 1999 och Larsson \& Moren 1988). 
alvård har funnits både före och efter efterkrigstiden (Meeuwisse, Sunesson \& Swärd, 2006) med möjligheter för privata företag att erbjuda sociala tjänster, något som sedan växer och ges ökade förutsättningar från början av 1990-talet (Harvey 2005). I efterkrigstid, när det socialdemokratiska partiet styrt i nästan 40 år, har det sociala arbetet i Sverige organiserats huvudsakligen inom kommuner och landsting, vilket har gett en hållbar kommunal organisation med ett organisatoriskt utrymme för utveckling av den sociala verksamheten, inte minst genom Kommunförbundets FoU verksamheter i kommunal regi. Under de senaste 20 åren har privata företag för äldreomsorg och sjukvård, utbildning och privata hälsoorganisationer, etablerats i samhället där den offentliga sektorn betalar för subventioneringen av tjänsterna och de privata företagen levererar tjänster (Löfstrand 2009). Det finns dock skillnader mellan motiven för den offentliga sektorn respektive den privata sektorn, som får effekter på det politiska överföringssystemet, och det är en fråga som blivit allt viktigare när det offentliga blivit mer privat (Schartau 2003, Socialstyrelsen 2010). Socialpolitiken är dock en av de viktigaste delarna $\mathrm{i}$ välfärden och är ett av de politiska områden som överför mest offentliga medel och alltid varit en viktig del av den politiska dagordningen. Nästan en tredjedel av den svenska BNP överförs till socialpolitik för att fördela pengar till sjuka, arbetslösa och pensionärer och till exempel betala för hälso- och sjukvård, äldreomsorg, barnomsorg och utbildning (Olofsson 2009).

Sverige har kännetecknats av en demokratisk socialism där staten tar en stor del av ansvaret för offentlig service via reformer som stöder ett solidariskt system (EspingAndersen 1990). Sverige har också beskrivits som en omfördelande socialism som inkluderar en progressiv beskattning i syfte att minska inkomstklyftorna och fattigdomen (Harvey 2005). Men sedan 1990-talet har Sverige rört sig mot vad Harvey anger som en "begränsad nyliberaliseringu. Nyliberalism beskrivs av Powell (2001:5) som två särskiljande element: libertarians och traditionalister och båda traditionerna är wunited in their support for capitalism and the renunciation of the welfare state». Privatisering av delar av pensionerna och förändrad relation till arbete och socialpolitik där avsikten är att tona ner den socialpolitiska profilen i relation till arbete (Elmér 2000) kan ses som exempel på en fortskridande nyliberalisering men fortfarande bevarar Sverige välfärdsstrukturerna, även om det har skett en ökning av ojämlikheten (Harvey 2005). Forskning visar att det opinionsmässiga stödet för välfärdsstaten är högt oavsett inkomstgrupp (Olsson 2009). Nyliberalisering sträcker sig dock utanför nationsgränserna och det sker en tydlig nyliberalisering i Västeuropa (Beck \& BeckGernsheim 2002). Det ifrågasätts dock $i$ början av 2000-talet om nationalstaterna kan behålla sina individuella skillnader. Uppfattningar har uttryckts att globaliseringen skulle urholka nationella gränser, påverka den ekonomiska politiken, det sociala livet, sociala problem, välfärdspolitiken och den praxis som utövas (Wilding 1997).

Den socialdemokratiska uppgörelsen rörande arbetslinjen var dock alltid baserad på antagandet att full sysselsättning var en prioritet och att välfärdsservice skulle kom- 
plettera den privata marknaden ekonomiskt snarare än att undergräva den (Wilson 1979:17). I Sverige finns det en lång tradition av arbetslinjen, vilket betyder att arbetet är prioriterat men utvecklingen har gått mot att individuella arbetssökande ska ges resurser så att de blir kapabla att konkurrera på arbetsmarknaden (Piippola 2003). Idén om den fulla sysselsättningen överges först i början av 1990-talet (Olofsson 2009).

Förändringar i socialpolitiken mot en mer aktiv privat marknad är inte något nytt utan en debatt som har förts under en längre tid, ofta relaterad till genomförandet av reformer om det offentliga ledarskapet som startade under senare delen av 80-talet i Sverige (Barry, Berg \& Chandler 2003) och som blev en inledning till ett nytt skede för privata initiativ i den offentliga sektorn. Mer konkurrens och privatisering av delar av den offentliga sektorn har pågått under de senaste 20 åren (Schartau 2003) vilket har lett till en föränderlig välfärdsstat som har som mål att omvandla, reformera, minska och modernisera (Clarke 2007). Detta ger enligt Aulenbacher och Riegraf (2010) tillsammans med Adult-Worker model dels en ny förståelse av välfärdsstaten, som innefattar samhällsmedborgare som är aktiva och ansvarsfulla men där det också finns människor som inte kan vara aktiva och därför inte längre uppnår aktivt medborgarskap (ibid.), och dels en annan bild av människan, homo economicus, som egoistiskt vill maximera sin egen nytta.

Även om reformen om det offentliga ledarskapet (NPM) kom till Sverige lite senare än till vissa andra länder, är det mitten av 1990-talet som många analytiker uppfattar som den tid då privata sektorn tog vid, med större betoning på prestation, effektivitet, ansvarighet och decentralisering (Barry, Berg \& Chandler 2003). Denna typ av reformer vilar dock ofta på idén att frihet, val, entreprenörskap och utförande är kärnan i dessa reformer, där ledarskapet ses som det som ska hålla samman alltsammans. Privatiseringen av delar av den offentliga sektorn under 1990-talet startade delvis på grund av en förändrad lagstiftning som innebar och öppnade upp möjligheter för kommunerna att skriva kontrakt med och lägga ut delar av sin verksamhet på privata företag (Löfstrand 2009). Olsson (2009) diskuterar att det i denna utveckling finns obesvarade frågor som vem tar hand om dem som har behov av mycket utbildning och dem som har sociala problem. Forskare har påpekat att upplösningen av det fordistiska samhället med dess mönster av produktion och institutionella förändringar har lett till en social obalans för den tredje industriella revolutionen (Aulenbacher \& Riegraf 2010).

När finanskrisen var ett faktum hösten 2007 aktualiserades på nytt socialpolitiken som ett område där förändringar kunde ske, och fokus på privata initiativ ökade. Spänningen mellan det offentliga och det privata blir tydligt vid ekonomiska kriser och har debatterats sedan 80-talet när diskussionen om det nya offentliga ledarskapet startade (Pollitt \& Bouchaert 2000). Omorganiseringen av välfärdsstaten leder till en omorganisering av de privata och semiprivata arrangemangen av den offentliga verksamheten i ett socialpolitiskt sammanhang. Bakom detta ligger hela idén om löner och inkomststruktur som ett viktigt antagande om solidaritet, en fördelning från dem 
som tjänar mest till dem som lever under sämre villkor. För att solidaritet ska föreligga förutsätts att skillnader i inkomster och sociala förhållanden inte blir för stort (Aulenbacher \& Riegraf 2010). När skillnaderna blir för stora blir privata försäkringar mer attraktiva för dem som tjänar mer och detta kan i sin tur leda till nedskärningar i de offentliga utgifterna (ibid.).

Utvecklingen på arbetsmarknaden i Sverige har under de senaste åren kännetecknats av en kraftig cyklisk nedgång, exempelvis har antalet anställda minskat med mer än 74000 människor mellan 2007 och 2009 (Socialstyrelsen 2010). Den relativa arbetslösheten har också, under samma period, ökat från 6,6 \% till 9,3 procent och enligt Sveriges kommuner och landsting har Sverige därför gått från en situation av relativt god balans på arbetsmarknaden till en situation med betydande reserver av outnyttjad arbetskraft. Situationen för de arbetslösa har utvecklats mot att många inte kan försörja sig på sin arbetslöshetsersättning. Det har blivit större ekonomiska skillnaderna mellan de som har arbete och de arbetslösa. Det är fyra av tio som får ekonomiskt bistånd på grund av arbetslöshet (ibid.). I samma rapport hävdas att nuvarande trend påminner en del om situationen på 1990-talet, när de kommunala insatserna för arbetslösa expanderade betydligt, och att den relativa arbetslösheten kommer att fortsätta att öka under 2010 och 2011.

I detta temanummer ligger fokus på områden som är centrala för välfärden och de sammanhang som många människor möter i ett samhälle som förändras, men också där förändringarna i samhället mot en mer nyliberal inriktning kan komma att mötas av motstånd av de som anser att välfärdstaten behövs. Dessa artiklar beaktar återverkningar på tre nivåer; makro som tar hänsyn till de stora förändringarna i samhället inom politiska, sociala och ekonomiska sammanhang: mezzo som utforskar organisatoriska frågor rörande ledning, personal och professionella, samt mikro som är inriktade på erfarenheterna hos de människor som i sista hand möter reformernas verkningar.

\section{Temanumrets artiklar}

Temanumrets sex artiklar² belyser förändringar och potentiella riktningar i samhället där välfärden genomgår en omställning mot ett tydligare nyliberalt samhälle, där den privata marknaden tar över delar av vad som tidigare har varit statens, landstingens och kommunernas ansvar vilket får konsekvenser för människor som är i behov av samhällets tjänster. Det är en förändring som påverkar välfärdsstatens aktörer inom organisationer som utbildning, socialt arbete och även påverkar arbetslösas situation generellt, och över tid kan dessa förändringar få betydande konsekvenser för välfärd och sociala rättigheter.

Brigitte Aulenbacher och Birgit Riegraf uppmärksammar med sin artikel »Välfärdstaten och det ekonomiska sammanbrottet: Föreställningar om prestationsförmåga,

2 Som gästredaktör vill jag tacka dem som har granskat artiklarna och gett konstruktiva synpunkter till författarna, och att granskarna likväl som författarna har följt de tidsramar som var givna för temanumret. 
deltagande och social rättvisa" vad som har skett under den senaste ekonomiska krisen med statliga ingripanden i Västeuropa. De analyserar hur offentlig välfärd påverkas av statliga ingripanden mot bakgrund av att investeringar delvis var finansierade från ekonomin inom välfärdsområdet. Författarna uppmärksammar också att det har pågått en omstrukturering av den allmänna välfärden under en ansenlig tid. De visar hur utvecklingen av den nuvarande situationen är relaterad till samtida frågor när de analyserar omstruktureringen av den offentliga sektorn. För att förstå förändringar använder de begreppen prestation och rättvisa när de sammanställer utvecklingen inom vård och socialt arbete.

Kazem Chaharbaghi sätter fokus på organisatoriska svårigheter och problem för ledare i sin artikel „Vision: en källa till innovation, illusion eller social kontroll?". Han visar att den offentliga sektorn är under inflytande av det nya offentliga ledarskapet vars teknik och tänkesätt kommer från den privata sektorn. Han hävdar att en vision av ledarna uppfattas som en inspirerande redogörelse för vad organisationen avser att bli och uppnå någon gång i framtiden. I organisationer, som är diversifierade och icke-hierarkiska till sin natur, finns det dock oklarheter om syftet och målet för organisationen. Varje försök att producera en vision leder till en otydlighet av vad som är innebörden av visionen. Han argumenterar att för att övervinna den återkommande olösta kris som varje organisation har, finns det behov av att behandla visionen på ett annorlunda sätt, med framsynthet som betonar insikt, reflektion och övervägande i syfte att avslöja alla dolda vinklar. Med den behandlingen kan en vision bli en källa till innovation i motsats till illusion och social kontroll. För att en vision ska bli en källa till innovation föreslår han en triangulär modell där erhållandet av offentliga tjänster kan förstås med stöd av professionella, byråkratiska och administrativa dimensioner.

Saila Piippolas artikel med rubriken "Arbetslinje - social trygghet eller risk?" består av forskning från ett regionalt område, Norrbotten. Det är forskning som hon har lång erfarenhet av och syftet med artikeln är att med begreppen social trygghet och risk visa hur arbetslöshet kan ge stora problem när krav finns att arbetslösa måste flytta där jobben finns. Den geografiska avgränsningen till Norrbotten avser att visa på komplexiteten i möjligheterna till arbete, samt arbetskraftens rörlighet och hur det påverkar människors vardag. Piippolas utgångspunkt är att kvinnor och män i Norrbotten lever i ett regionalt sammanhang där arbetsmarknaden i huvudsak domineras av stål- och träindustri i en del av regionen och handel och sociala tjänster i en annan del av regionen. Samtidigt är det högre arbetslöshet jämfört med resten av Sverige. Hon analyserar i sin artikel hur arbetslinjen som betonar ekonomisk trygghet innebär en risk och hotar den sociala tryggheten när jobben leder till flyttning från ett socialt nätverk.

Karolina Parding och Andreas Liljegren diskuterar i sin artikel "Ändrad styrning av välfärdsprofessioner - exemplet evidensbasering i socialt arbete» hur olika styrningsideal leder till förändringar för professionella, och vilka konsekvenser evidensbaserad kunskap får för socionomens dagliga arbetsliv. Artikelns syfte är skapa 
en teoretisk modell för hur styrning kan förstås genom att föra in Evetts två idealtypiska logiker (kontroll av det professionella arbetet och yrkes- och organisatorisk professionalism) i det professionella arbetets tre aspekter; att diagnostisera, att resonera och att àtgärda. Deras andra syfte är att tillämpa denna modell som ett instrument för utvärdering och bedömning där avsikten är att öka förståelsen hur förändrade styrningsideal kan få effekter för professionellt arbete. En av deras slutsatser är att evidensbaserad praktik kan innebära nya vägval för socionomerna i relation till yrkesutövningen, samt att det finns såväl möjligheter som svårigheter beroende av vilka val som görs.

Barbro Blomberg, Lena Widerlund och Ann-Marie Lindqvist visar i sin artikel "Stöd och service till personer med utvecklingsstörning. En studie om förändringar i Sverige och Finland mellan åren 1990 och 2010« att strukturella förändringar av stöd och service har gett effekt på det dagliga livet för de personer som har en utvecklingsstörning. Det har skett stora förändringar när det gäller stöd och service till denna grupp i både Sverige och Finland mot bakgrund av organisationernas målsättningar för dessa grupper. Konsekvenserna av dessa förändringar har lett till både möjligheter och dilemman. Några slutsatser är att det finns intentioner som inte genomförs därför att strukturer, som författarna kallar realiteter som ekonomi och organisationer, utgör hinder men även för att tidigare kulturer fungerar som barriärer i förverkligandet av brukarnas möjligheter till delaktighet.

Katarina Andersson visar med sin avslu- tande artikel för detta temanummer "Valfrihet och mångfald - ett dilemma för hemtjänsten" hur omsorg om äldre i en kommun har genomgått omfattande förändringar. Syftet med artikeln är att belysa hur både brukare och personal ser på de omsorgsinsatser som utförs, och problematisera hur valfrihet och mångfald upplevs och hanteras $i$ en kommun som infört kundvalssystem i hemtjänsten. I artikeln diskuteras äldreomsorgens förändringar under senare år och även hur olika företag har utvecklat olika modeller för urval av kunder i de kommuner där valfrihet och konkurrens mellan företag har anammats. Centrala frågor är hur vård, mångfald och jämställdhet kan förstås inom detta område. Hon pekar bland annat på hur kundval, som utgör en del av den privata verksamheten och del av socialpolitiken, är en del av en kvasimarknad som verkar under andra förutsättningar än den fria marknaden. Mot bakgrund av denna kvasikontext diskuteras valfriheten som begränsad och villkorad i kundvalssystemet, och frågan som reses är "Vad är det egentligen för valfrihet som är möjlig i detta system?" Några slutsatser är att kundval inte har påverkat brukarinflytandet i praktiken och att den ökade individualiseringen med ökad valfrihet för kunderna snarare riskerar att osynliggöra ett etiskt förhållningssätt bland personalen.

Dessa artiklar visar hur omfördelningar mellan det privata och det offentliga får konsekvenser för enskilda och organisationer och leder till att tidigare invanda föreställningar om vad välfärdsstaten och det offentliga ansvarar för, förändras mot ett mer individualiserat risksamhälle. 


\section{Referenser}

Aulenbacher, Brigitte \& Riegraf, Birgit (2010) The Financial Meltdown and the Crisis of Reproduction: Imaginations of Performance, Participation and Social Justice Keynote, Dilemmas for Human Services 2010, Changes and new directions in Human services, 14th International Research Conference, Luleå University of Technology 10 - 11 September 2010

Barry, Jim; Berg, Elisabeth \& Chandler John (2003) "Managing intellectual labour in Sweden and England."Cross Cultural Management Vol.10, Nr.3 Sid:3-22.

Beck, Ulrich \& Beck-Gernsheim, Elisabeth (2002) Individualization London: SAGE.

Clarke, John (2007) Changing Welfare changing states new directions in social policy. London: SAGE.

Danermark, Bert \& Kullberg, Christian (1999) Samverkan - Välfärdsstaten nya arbetsform, Lund: Studentlitteratur.

Elmér, Åke, Blomberg, Staffan, Harrysson, Lars \& Petersson Jan (2000) Svensk Socialpolitik. Lund: Studentlitteratur.

Esping-Andersen, Gösta (1990) The Three Worlds of Welfare Capitalism, Cambridge: Polity Press.

Harvey, David (2005) A Brief history of Neo-Liberalism. New York: Oxford University Press.

Holmberg, Ingalill \& Henning, Roger (2003): Offentligt ledarskap - om förändring, förnyelse och nya ledarideal. Lund: Studentlitteratur.

Jacobson-Libietis Vivi (2010) Kommunerna och arbetsmarknadspolitiken En redogörelse för aktuell lagstiftning och samverkansformer, Sveriges kommuner och Landsting.

Larsson, Håkan \& Moren, Stefan (1988) Organisationens mänskliga insida. Om det sociala arbetets utvecklingsmöjligheter. Umeå: Studier i socialt arbete vid Umeå universitet $\mathrm{nr} 7$.

Löfstrand, Ingrid (2009) Professionellt föräldraskap - Samhälleliga förutsättningar för familjehem för tonåringar, Luleå: Luleå Tekniska Universitet, Licentiatuppsats.

Meeuwisse, Anna, Sunesson, Sune \& Swärd, Hans (2006) Socialt arbete. Stockholm: Natur \& Kultur.

Olofsson, Jonas (2009) Socialpolitik varför, hur och till vilken nytta? Stockholm: SNS förlag.

Pippola Saila (2003) Gränsvandrare positionerar sig på arbetsmarknaden: handlingsutrymmen för arbetssökande inom ett begränsat geografiskt område, Luleå: University of Technology. Doktorsavhandling.

Pollitt, Christopher \& Bouchaert, Gert (2004) Public management Reform, A comparative analysis. New York: Oxford University Press.

Powell, Fred (2001) The Politics of Social Work. London: SAGE.

Schartau, Mai-Brith (2003) „Ledarskap i välfärdspluralism" I Offentligt ledarskap - om förändring, förnyelse och nya ledarideal. Holmberg, I. \& Henning, R. (red.) Lund: Studentlitteratur.

Socialstyrelsen (2010) Statistik över försörjningshinder och ändamål med ekonomiskt bistånd, Redovisning av en testinsamling 2009, Sveriges kommuner och landsting

Wilding, Paul (1997) "Globalization, Regionalism and Social Policy", Social Policy and Administration, 31(4), 410-428.

Wilson, Dorothy (1979) The Welfare State in Sweden: A study in comparative social administration, London: Heinemann. 